\title{
Sleep Efficiency is Inversely Associated with Brachial Artery Diameter and Morning Blood Pressure in Midlife Adults, with a Potential Sex-Effect: A Short Comment [Letter]
}

\author{
Reza Rastmanesh (iD) ${ }^{1,2}$ \\ 'The Nutrition Society, London, UK; \\ ${ }^{2}$ American Physical Society, College Park, \\ MD, USA
}

\section{Dear editor}

I read with interest the article by Thosar et al. ${ }^{1}$ Similar findings were reported before. ${ }^{2}$ I was troubled by the logic of the conclusion stating that disturbed sleep could be implicated as a mechanism in the morning increase in adverse $\mathrm{CV}$ events because their study design is not appropriate for such a mechanistic conclusion.

Firstly, while sleep efficiency is significantly negatively associated with baseline brachial artery diameter, ${ }^{1,2}$ this later itself is a function of endogenous nitric oxide (NO) production. ${ }^{3}$ Here, it is very crucial to differentiate between differential roles of vessel distensibility vs diameter.

Brachial artery diameter is not static. It varies over time as a function of the interactive influence of sympathetic activation on brachial artery distensibility compared to its diameter. ${ }^{3}$ Sympathetic excitation decreases the distensibility of the brachial artery independently of concurrent changes in diastolic diameter, HR, and $\mathrm{BP}^{2}$ Since NO interactions determine brachial artery mechanics in humans, it is important to note the differential role of vascular reactivity in men and women of reproductive age and different levels of adiposity and exercise. For instance, exercise vasodilation is reported to be significantly greater in women due to the differential NO synthase and cyclooxygenase signaling. ${ }^{4}$ All these complexities add uncertainty to the challenges of establishing a reliable result. However, the authors have neglected to take into account these fundamental differences.

Even more troubling is the role of sex differences in the contribution of NO to FMD. Heterogeneous vasodilator pathways underlie FMD in men and women. There are findings suggesting that radial artery FMD is not fully or uniformly NO dependent in either men or women and that there is heterogeneity in the pathways underlying the conduit dilatory response to ischemia. ${ }^{5}$ The fact that Thosar et al ${ }^{1}$ found no significant association with HR or FMD supports this very argument.

Thirdly, they state that if findings persist in adults with existing CV disease, then disturbed sleep could be implicated as a mechanism for the morning increase in adverse $\mathrm{CV}$ events. I argue that this is not quite the case. To explore the attributed mechanism, a minimum level of intervention and control groups are needed; otherwise, within a counterfactual line of reasoning, it is quite possible to expect
Correspondence: Reza Rastmanesh \#6, Physicians Building, Sarshar Alley, Vali Asr Street, Tajrish, Tehran, 1961835555, Iran

Email r.rastmanesh@gmail.com 
that at least a fraction of patients could concomitantly have symptoms from both adverse CV events and sleep disorders with no involvement of brachial artery diameter and altered morning BP. Ignorance of this issue could obscure any conclusion.

Thus, it would be over simplistic to consider an independent role for sleep efficiency in mechanisms leading to adverse CV events solely based on their correlational study. No matter how large sample size $n$ we choose or how homogenous/heterogeneous our participants look. No evidence of NO measurement or other factors which determine brachial artery diameter and distensibility is provided by Thosar et al, ${ }^{1}$ and it is difficult to judge if associations between sleep efficiency and brachial artery diameter are an artifact or a genuine relationship.

\section{Disclosure}

The author reports no competing or conflicts of interest for this communication.

\section{References}

1. Thosar SS, Chess D, Bowles NP, et al. Sleep efficiency is inversely associated with brachial artery diameter and morning blood pressure in midlife adults, with a potential sex-effect. Nat Sci Sleep. 2021;13:1641-1651. doi:10.2147/NSS.S329359

2. Adawi M, Sabbah F, Tzischinsky O, et al. Sleep disorders and vascular responsiveness in patients with rheumatoid arthritis. J Intern Med. 2020;288(4):439-445. doi:10.1111/joim.13087

3. Salzer DA, Medeiros PJ, Craen R, et al. Neurogenic-nitric oxide interactions affecting brachial artery mechanics in humans: roles of vessel distensibility vs. diameter. Am J Physiol Regul Integr Comp Physiol. 2008;295(4):R1181-R1187. doi:10.1152/ajpregu.90333.2008

4. Kellawan JM, Johansson RE, Harrell JW, et al. Exercise vasodilation is greater in women: contributions of nitric oxide synthase and cyclooxygenase. Eur J Appl Physiol. 2015;115(8):1735-1746. doi:10.1007/s00421-015-3160-6

5. Parker BA, Tschakovsky ME, Augeri AL, et al. Heterogenous vasodilator pathways underlie flow-mediated dilation in men and women. $\mathrm{Am}$ J Physiol Heart Circ Physiol. 2011;301(3):H1118-H1126. doi:10.1152/ ajpheart.00400.2011

Dove Medical Press encourages responsible, free and frank academic debate. The content of the Nature and Science of Sleep 'letters to the editor' section does not necessarily represent the views of Dove Medical Press, its officers, agents, employees, related entities or the Nature and Science of Sleep editors. While all reasonable steps have been taken to confirm the content of each letter, Dove Medical Press accepts no liability in respect of the content of any letter, nor is it responsible for the content and accuracy of any letter to the editor.

Nature and Science of Sleep

\section{Dovepress}

\section{Publish your work in this journal}

Nature and Science of Sleep is an international, peer-reviewed, open access journal covering all aspects of sleep science and sleep medicine, including the neurophysiology and functions of sleep, the genetics of sleep, sleep and society, biological rhythms, dreaming, sleep disorders and therapy, and strategies to optimize healthy sleep.
The manuscript management system is completely online and includes a very quick and fair peer-review system, which is all easy to use. Visit http://www.dovepress.com/testimonials.php to read real quotes from published authors. 